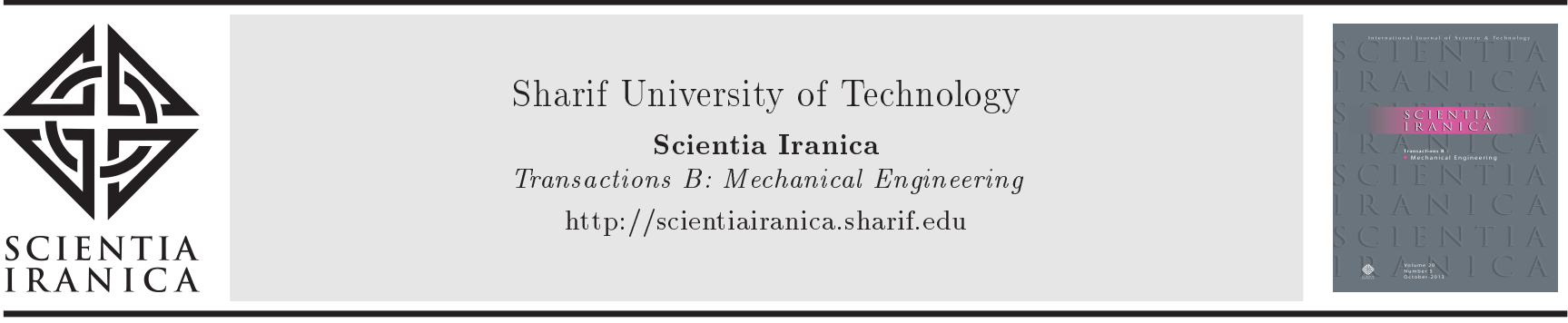

\title{
Three dimensional prediction of stability lobes in end milling of thin-walled structures based on tool and workpiece dimensions
}

\author{
M. Mahboubkhah ${ }^{a, *}$, M.R. Movahhedy ${ }^{b}$, and A. Jodeiri Feizi ${ }^{a}$ \\ a. Department of Mechanical Engineering, University of Tabriz, Tabriz, P.O. Box 51666-16471, Iran. \\ b. Department of Mechanical Engineering, Sharif University of Technology, Tehran, Iran. \\ Received 6 June 2020; received in revised form 11 February 2021; accepted 24 May 2021
}

\author{
KEYWORDS \\ Thin-walled \\ structures; \\ Milling chatter \\ stability; \\ Machining geometrical \\ parameters; \\ Three dimensional \\ stability lobe \\ diagrams.
}

\begin{abstract}
Nowadays, researchers are very interested to investigate the dynamic behavior of thin-walled structures during the machining process due to their broad application in aerospace, automotive industries, etc. One of the main problems in the machining of thinwalled structures is unstable chatter vibrations, which causes poor machined surface quality and decreases the system life span. Therefore, the main aim of this paper is to propose a practical method to solve the chatter instability problem during the milling process of thinwalled components. To this end, first, the effects of geometrical parameters like workpiece height, thickness, tool overhang, diameter, and their ratios on the chatter stability are investigated. Based on the mentioned parameters, three-dimensional Stability Lobe Diagrams (SLDs) are presented for the first time in which one can use the diagrams to switch the unstable machining process to a stable one by changing the values of the system parameters. Finally, the results obtained by the experimental test show that the presented threedimensional diagrams can be utilized to avoid chatter instability in the milling process.

(C) 2022 Sharif University of Technology. All rights reserved.
\end{abstract}

\section{Introduction}

Monolithic thin-walled structures and components are widely used in different industrial applications such as aerospace and automotive industries. High-speed end milling is often used to give the desired shape to these components. Because of the low dynamic rigidity of these parts as well as high machining speed, the probability of chatter occurrence during machining of these parts increases $[1,2]$. Chatter is a dynamic instability the root of which is the self-excited vibrations resulting from tool-workpiece interactions in machining

*. Corresponding author. Tel.: +98-41-33392462 E-mail address: mahboobkhah@tabrizu.ac.ir ( $M$. Mahboubkhah)

doi: $10.24200 /$ sci. 2021.56130 .4565 processes. This phenomenon reduces the Material Removal Rate (MRR) as well as the efficiency of the machining process and results in low surface quality, high machining noise, tool wear, and, if not controlled, breakage of tool or damage to workpiece [3-5]. Therefore, it is of absolute significance to prevent chatter.

Initial studies on this phenomenon have been done by Tobias and Fishwick [6] and Tlusty and Polacek [7]. They recognized the mechanism of the chatter phenomenon and presented its mathematical model with a delay differential equation. Tang and Liu [8] investigated the effect of the helix and cutting angle on the stability of the milling process. They found that increasing the helix and cutting angle enhanced stability. Seguy et al. [9] have investigated the chatter phenomenon in the milling of thin-walled parts using the Finite Element Method (FEM). Their findings showed that milling with a long tool with 
a small diameter or machining highly flexible walls greatly increases the probability of chatter. Gonzalo et al. [10] simulated the machining process of thinwalled aluminum parts. Their simulation was based on a mechanistic model in the time domain. In their research, they used a Finite Element (FE) model of the workpiece for defining the dynamic properties of the thin-walled parts under machining. Campa et al. $[11,12]$ solved the variable dynamic problem of thinwalled parts by computing three-dimensional Stability Lobe Diagrams (SLDs). In their research, the third dimension of the diagram is the position of the tool along the workpiece. Song et al. [13] similarly proposed a method to predict the stability of the milling of thinwalled parts, where changes in dynamic characteristics are correlated with tool position. They extracted the Frequency Response Function (FRF) from the FE model and extracted the SLD by continuously scanning the dynamic properties of the FE model during machining. To obtain optimal machining parameters for maximum MRR in the machining of thin-walled parts, Tang and Liu [14] derived a 3D SLD the axes of which represented spindle speed, axial cutting depth, and radial Depth Of Cut (DOC). Ismail and Ziaei [15] used two types of online and offline measurement methods to avoid chatter in the machining of flexible turbine blades in a five-axis machine. Bravo et al. [16] performed a dynamic simulation of the system based on the relative FRF, which sums up the response functions of the machine and the workpiece. Through machining experiments, they proved that SLDs obtained in this way are more accurate than those obtained with either the machine tool response function or the workpiece response function alone. Mañé et al. [17] analyzed the dynamic interaction between two systems of machine tool-tool and machine tool-thin walled part via the FEM to predict the stability of the machining process. The relationship between chatter instability and surface roughness variations in the milling of thin-walled parts was studied by Seguy et al. [18]. Atlar et al. [19] studied the stability of the machining process by using the relative Transfer Function (TF) between the tool and the workpiece. They studied the effect of the workpiece variable dynamics, different cutting conditions, and machining strategies on the MRR. Zhang et al. [20] used multiple structural mode interactions rooted in the cutting force to extract the milling stability boundaries of the flexible workpiece. The obtained results revealed that in the machining of flexible components, several vibrational modes of the flexible structure affect machining stability. The machining time for a turbine blade was reduced from 35 minutes to 19 minutes when the milling of thinwalled parts was based on a predicted SLD in which the variable dynamics of the workpiece were taken into account in addition to those of the tool, according to Budak et al. [21]. Significant reduction in the time of machining along with avoidance of chatter on the finished surface of the workpiece indicates that incorporation of the variable dynamics of the workpiece in the milling of thin-walled parts is essential. Using operational modal analysis and solely based on system response data measured by accelerometer during machining, Powałka and Jemielniak [22] extracted SLDs. Their results showed that the SLDs obtained from this method are not sensitive to the coefficients of the cutting force model. Wan et al. [23] provided an effective way to improve the stability of the milling of thin-walled parts. In the proposed method, mass was added to the workpiece to improve the stability behavior of the system. In another paper, Wan et al. [24] showed that the stability of machining of thinwalled parts could be improved by applying pre-stress to the workpiece. Yan and Zhu [25] investigated the stability of thin-walled parts on the milling process based on improved multi-frequency solutions. The results revealed that improved multi-frequency solution be more accurate than zero-order analysis. Zhu et al. [26] optimized milling parameters by genetic algorithm based on process damping. Their achievement provided a theoretical foundation and reference for the milling mechanism research. Wan et al. [27] studied the effect of vibration assistance on chatter stability in the milling process. The results revealed that the vibration assistance does not improve the critical DOC, but generates new stability lobes between the original two adjacent lobes corresponding to no vibration assistance. Liu et al. [28] investigated the chatter stability of thin-walled parts in milling utilizing relative $\mathrm{TF}$ and process damping. Their results showed that the process damping can significantly improve the stability of the low-speed region. Liu et al. [29] proposed a new method to detect the milling chatter based on variational mode decomposition and energy entropy. The simulation and experimental results revealed that the proposed approach can effectively detect chatter. Wan et al. [30] presented an active chatter suppression method by using a sliding mode control approach and electromagnetic actuator. The obtained results showed that the chatter-free domain is significantly enhanced in a wide spindle speed range. Wu et al. [31] studied the stability behavior of Ti-6Al-4V thinwall in the milling process by considering tool wear and thermal-mechanical coupling. They presented a novel predictive model to compute the cutting-induced thermal-mechanical loads and workpiece deflection in the milling Ti-6Al-4V components. Finally, a series of cutting experiments were conducted to validate the proposed method. Yan et al. [32] investigate chatter stability in milling with variable cross-sections and a large length-to-diameter ratio tool holder. They proposed a new tool holder with high dynamic stiffness 
to improve the chatter stability. The theoretical results show that increasing dynamic stiffness can improve the stability behavior of the system. Altintas et al. [33] reviewed the dynamics of machining and the fundamentals of chatter stability laws developed in the frequency and discrete-time domains. In their research, Zhu and Liu [34] conducted a systematic review of chatter, focusing on offline chatter prediction, online chatter detection, and chatter suppression techniques. Dun et al. [35] propose a numerical difference method for predicting stability in milling based on the AdamsBashforth scheme. Moreover, they proposed a multimodal scheme of the numerical approach. Dang et al. [36] proposed a theoretical approach to analyzing the dynamics of the milling process of the pocketshaped thin-walled workpieces with viscous fluid to prevent chatter vibrations. Zhu et al. [37] presented a method for detection of chatter for peripheral milling thin-walled workpieces by using sample entropy and energy entropy. The findings showed that chatter is essentially an entropy-increasing phenomenon. It means that sample entropy and energy entropy will increase when the cutting process chatters.

According to previous studies, vibrational tests can be used to determine the stability of a system. However, there are few manufacturing workshops in which both test equipment and vibration specialists are available. As a result, vibration analysis is not a practical method for predicting the stable zone of machining in production workshops. Therefore, this research work aims to develop a method to predict the stability of the thin-walled parts in end milling based on the geometrical parameters of the machining system such as the length and the diameter of the tool and the size of the workpiece. It should be noted that, due to the availability of dimensional measurement equipment in almost all machining workshops, the presented method is applicable in all machining workshops. As a result, for the first time in this study, three-dimensional SLDs based on the geometrical parameters of the workpiece and tool are presented, in which one can avoid chatter instability by using the mentioned three-dimensional SLDs and dimensional measuring tools.

This paper is organized as follows: first, the dynamic model of the workpiece and the machine tool is constructed and the FRFs of the system are calculated. Next, three-dimensional SLDs diagrams based on the geometrical parameters of the workpiece and the machine tool are extracted. Finally, an example of the application of the diagrams to prevent chatter instability is shown by performing an experimental test.

\section{The dynamic model of the system and extracting the relative TF}

In this study to model the dynamic behavior of the

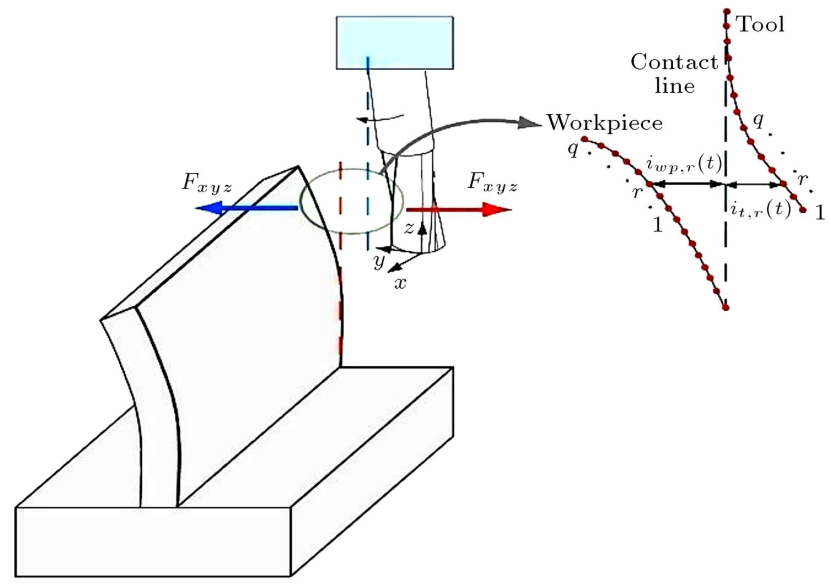

Figure 1. Relative displacement of tool and workpiece [38].

milling process of thin-walled parts, the relative displacement of the tool and workpiece are considered (Figure 1).

In terms of geometry, the workpiece deformation in the $x$ direction can be ignored compared to that in the $y$ direction. The relative displacement of the tool and the workpiece in this case is the workpiece displacement plus the tool displacement in the $y$ direction. Therefore, the relative TF of the system in the $y$ direction can be calculated from Eq. (1) [16]:

$$
\phi_{\text {relative }}(y y)=\phi_{m m}(y y)+\phi_{w p}(y y) \text {. }
$$

In Eq. (1), $\phi_{m m}(y y)$ and $\phi_{w p}(y y)$, are the TFs of the machine tool and the workpiece in the $y$ direction, respectively. Therefore, to obtain the stable zone, the TFs of the workpiece and tool must first be extracted.

\subsection{Workpiece TF}

As shown in Eq. (2), in this investigation the multiple degrees of freedom TF of the workpiece is used:

$$
\phi_{j k}=\sum_{r=1}^{n} \frac{\left\{\varphi_{j r}\right\}\left\{\varphi_{k r}\right\}}{\varpi_{r}^{2}-\varpi^{2}+\eta_{r} \varpi_{r} \varpi i},
$$

where $\omega_{r}$ is the natural frequencies, $\left\{\varphi_{r}\right\}$ are the mass normalized mode shapes, $\eta_{r}$ is the structural damping ratio of $r$ th mode. The modal parameters of the flexible part, which can be calculated using FE analysis, are required to determine the workpiece $\mathrm{TF}$, as shown in the above equation. Here, Abaqus software has been utilized to determine the mentioned parameters of the workpiece. Therefore, a plate with dimensions of $65 \times 40 \mathrm{~mm}$, and a thickness of $6 \mathrm{~mm}$ is modeled in Abaqus using the S4R shell element. The material was 7075 aluminum alloy, the Young modulus was $70 \mathrm{GPa}$ and Density was $2800 \mathrm{~kg} / \mathrm{m}^{3}$. By using the FEM software, the first three natural frequencies of the workpiece have been calculated and presented in 
Table 1. The first three natural frequencies of the workpiece in $\mathrm{Hz}$.

\begin{tabular}{ccc}
\hline Mode no. & Current study & Leissa [39] \\
\hline 1 & 1171.4 & 1162.5 \\
2 & 3903.1 & 4187.2 \\
3 & 6139.1 & 7168.8 \\
\hline
\end{tabular}

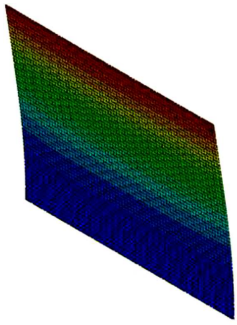

1st mode

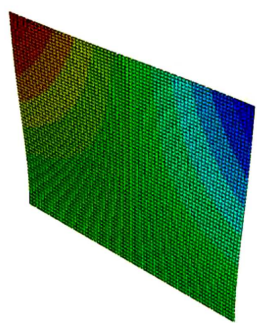

2nd mode

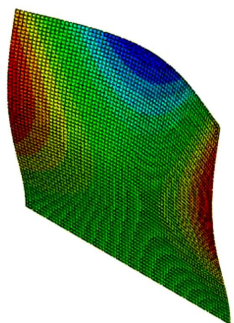

3rd mode
Figure 2. First three mode shapes of the workpiece.

Table 1. Also, the first three mode shapes of the plate are illustrated in Figure 2. Three frequencies obtained using Abaqus software were compared with theoretical results obtained in [39] to ensure proper modeling of the workpiece in FEM software and accuracy of the results.

To acquire the damping ratio, the experimental modal test was performed. The plate was subjected to external excitation for this purpose, as shown in Figure 3, and the acceleration of a specific point on it was measured. The equipment used for the modal test was the 222B miniature accelerometer with a sensitivity of $16 \mathrm{pC} / \mathrm{g}$ and an HP2035 dual-channel analyzer. The FRF of the workpiece are obtained in the above modal test as well as in simulations shown in Figure 4. It is worth noting that, the first three damping ratios of the workpiece were obtained by using modal software (Table 2).

\subsection{Tool $T F$}

To determine the relative $\mathrm{TF}$ of the system, the frequency response of the tool is needed, which can be obtained as follow.

First, the tool is modeled as a cantilever beam

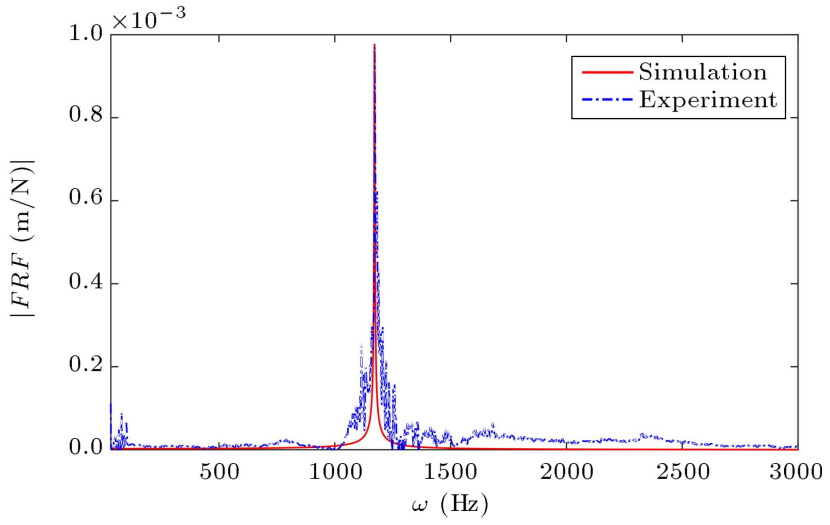

Figure 4. Frequency Response Function (FRF) of the workpiece in the $y$ direction.

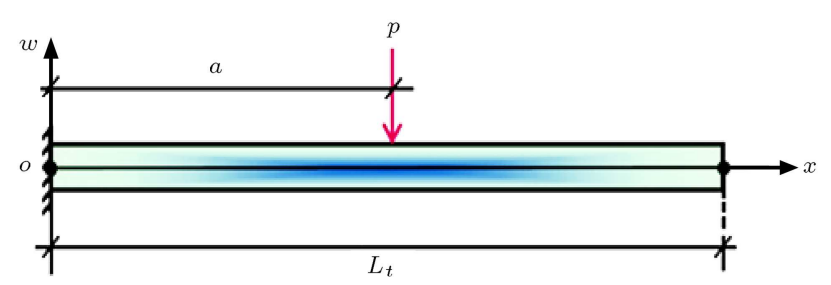

Figure 5. Schematic model of the tool.

Table 2. First three damping coefficients of the workpiece.

\begin{tabular}{cc}
\hline Mode no. & Damping ratio (\%) \\
\hline 1 & 0.25 \\
2 & 0.41 \\
3 & 0.61 \\
\hline
\end{tabular}

as illustrated in Figure 5. Then the motion equations of a cantilever are derived and the time response of the tool which is subjected to impact force is obtained. Finally performing the Fourier transform on displacement signal, the frequency response of the tool is achieved.

The vibrational equation of the beam under the excitation of the force $P$ can be expressed as [40]:
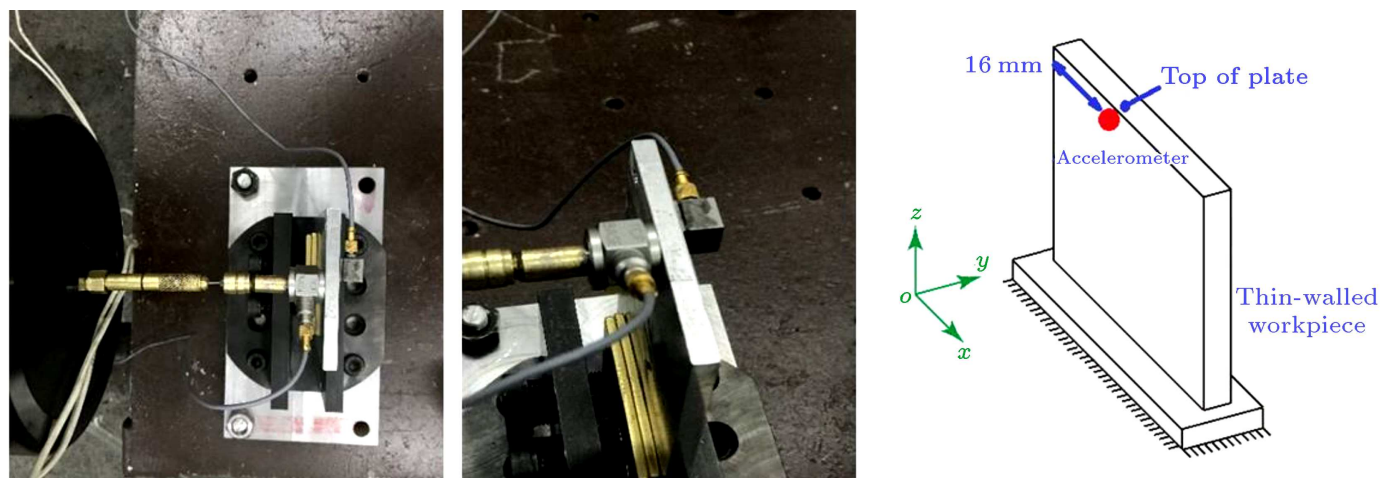

Figure 3. Workpiece modal test. 


$$
E I \frac{\partial^{4} w(x, t)}{\partial x^{4}}+c \frac{\partial w(x, t)}{\partial t}+m \frac{\partial^{2} w(x, t)}{\partial t^{2}}=p \delta(x-a)
$$

where $c$ is the Rayleigh damping coefficient, $w$ is the displacement of the beam at point $x, E I$ is the bending stiffness, and $m$ is the mass per unit length of the cantilever. The boundary conditions can be expressed as:

$$
\begin{aligned}
& \left.\frac{\partial w}{\partial x}\right|_{x=0}=0,\left.\quad w\right|_{x=0}=0, \\
& \left.\frac{\partial^{2} w}{\partial x^{2}}\right|_{x=L_{t}}=0,\left.\quad \frac{\partial^{3} w}{\partial x^{3}}\right|_{x=L_{t}}=0 .
\end{aligned}
$$

The solution of Eq. (3) can be expressed as follows:

$$
w(x, t)=\sum_{r=1}^{\infty} \psi_{r}(x) \chi_{r}(t)
$$

where $\chi_{r}(t)$ is the modal coordinate and $\psi_{r}(x)$ is:

$$
\begin{aligned}
\psi_{r}(x)= & D_{r}\left[\cosh \left(\frac{\kappa_{r}}{L_{t}} x\right)-\cos \left(\frac{\kappa_{r}}{L_{t}} x\right)\right. \\
& \left.-v_{r}\left(\sinh \left(\frac{\kappa_{r}}{L_{t}} x\right)-\sin \left(\frac{\kappa_{r}}{L_{t}} x\right)\right)\right],
\end{aligned}
$$

where:

$$
v_{r}=\frac{\sinh \kappa_{r}-\sin \kappa_{r}}{\cosh \kappa_{r}+\cos \kappa_{r}}
$$

$\kappa_{r}$ is acquired from the following equation:

$$
1+\cosh \kappa_{r} \cos \kappa_{r}=0 .
$$

The natural frequency of the system is expressed through the following equation:

$$
\omega_{r}=\kappa_{r}^{2} \sqrt{\frac{E I}{m L_{t}^{4}}} .
$$

Eq. (10) can be derived by substituting Eq. (5) into Eq. (3) and applying the orthogonality criteria:

$$
\begin{aligned}
\frac{d^{2} \chi_{r}(t)}{d t^{2}} & +2 \zeta_{r} \omega_{r} \frac{d \chi_{r}(t)}{d t}+\omega_{r}^{2} \chi_{r}(t) \\
= & \frac{1}{m} \int_{0}^{L} \psi_{s}(x) p(t) \delta(x-a) d x, \quad r=1,2,3 .
\end{aligned}
$$

In the above relation the damping ratio can be computed from Eq. (11):

$$
2 \zeta_{r} \omega_{r}=\frac{c}{m} .
$$

The time response of the cantilever with $L_{t}=60 \mathrm{~mm}$, $r=10 \mathrm{~mm}, E=200 \mathrm{GPa}, \rho=7800 \mathrm{~kg} / \mathrm{m}^{3}$ is derived by using the Runge-Kutta 4th order method. One can

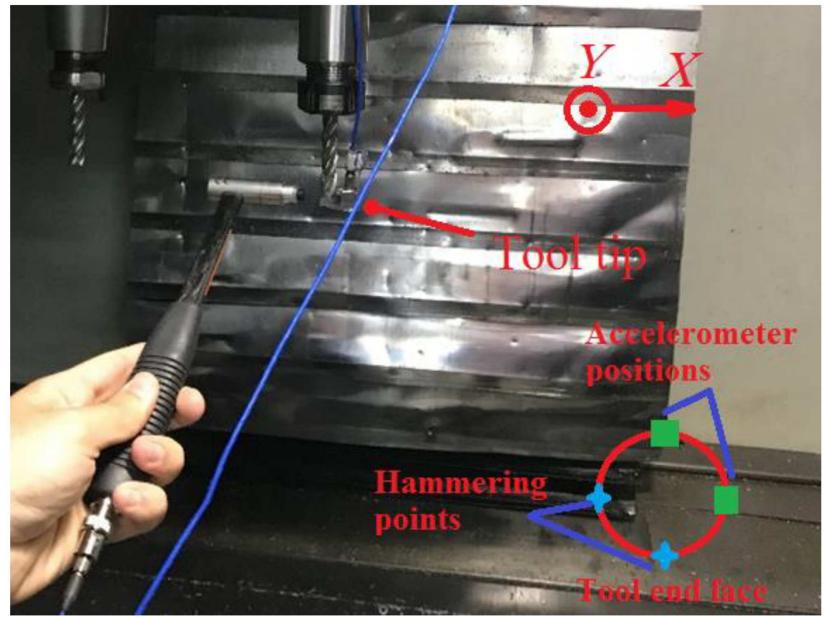

Figure 6. Tool modal test.

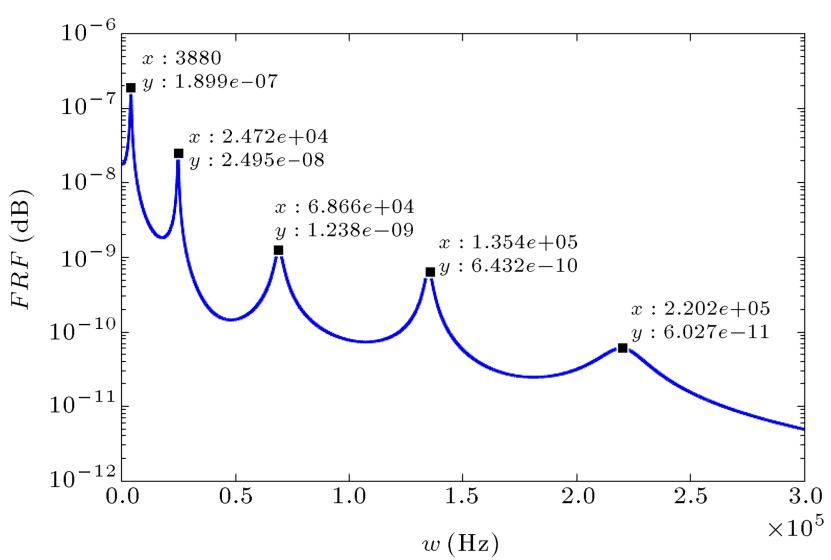

Figure 7. Frequency Response Function (FRF) of the tool in $x$ direction (feed direction).

obtain the FRF of the tool by transferring the time response to the frequency domain by applying a fast Fourier transform.

It should be noted that to acquire modal damping, impact testing is performed (Figure 6). For this purpose, after setting the tool on the milling machine, the system was excited using a hammer and its acceleration was measured. The equipment used for the modal test were load cell model 8200 with $4 \mathrm{pC} / \mathrm{N}$ sensitivity, the 8202 hammers, the 222B miniature accelerometer made by Endevco with a sensitivity of $0.16 \mathrm{pC} / \mathrm{g}$, and a 2035 dual-channel analyzer made by Bruel and Kjaer company.

After measuring the acceleration of the tool in the $x$ (feed) direction, the first five damping ratios of the tool are computed Eq. (8).

After figuring out the damping ratios and inserting them in the model, the time response of the tool displacement is computed and by applying the fast Fourier transform, the FRF of the system is obtained according to Figure 7.

Also, to ensure the accuracy of the model, the 


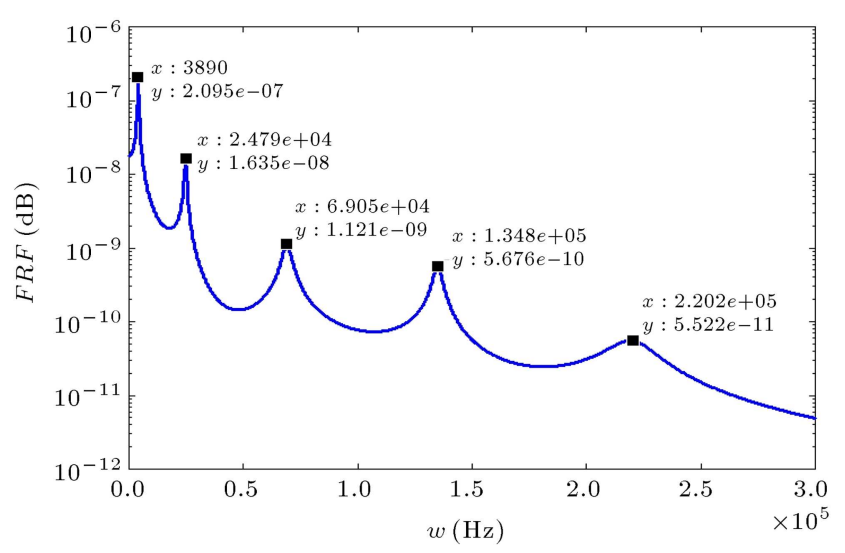

Figure 8. Frequency Response Function (FRF) of the tool in $y$ direction.

Table 3. First five damping ratios of the tool.

\begin{tabular}{cc}
\hline Mode no. & Damping ratio (\%) \\
\hline 1 & 4.7 \\
2 & 0.9 \\
3 & 2.3 \\
4 & 0.8 \\
5 & 1.3 \\
\hline
\end{tabular}

Table 4. Natural frequencies of the tool obtained via analytical method.

\begin{tabular}{cl}
\hline Mode no. & Analytical $(\mathbf{H z})$ \\
\hline 1 & 3935.55 \\
2 & 24663.70 \\
3 & 69059.09 \\
4 & 135328.28 \\
5 & 223707.31 \\
\hline
\end{tabular}

natural frequencies of the tool are analytically calculated (Table 3). As shown in Figure 7, the natural frequencies obtained from the fast Fourier transform of the time response of the system are in good agreement with analytical values (Table 4 ), which indicates the accuracy of the tool modeling.

Using the same method, the FRF of the tool is measured along the $y$ direction (Figure 8). It is noteworthy that the flexibility of the machine tool in the $z$ direction (spindle axis) is ignored.

By comparing Figures 7 and 8, it can be seen that the dynamic behavior of the tool is almost equal in $x$ and $y$ directions.

\section{Chatter stability analysis}

According to the study of Budak and Altintas [41] on milling process stability, the SLDs can be obtained using the equation below:

$$
b_{l i m}=-\frac{2 \pi \Lambda_{R}}{N K_{t}}\left(1+\kappa^{2}\right),
$$

where $N$ is the number of cutter teeth, $K_{t}$ is the coefficient of tangential cutting force, and $\Lambda_{R}$ is the real part of system eigenvalues that is obtained as follows:

$$
\Lambda=-\frac{1}{2 a_{0}}\left(a_{1} \pm \sqrt{a_{1}^{2}-4 a_{0}}\right),
$$

where:

$$
\begin{aligned}
& a_{0}=\phi_{\text {relative }}\left(i \omega_{c}\right) \phi_{\text {relative }}\left(i \omega_{c}\right)\left(\alpha_{x x} \alpha_{y y}-\alpha_{x y} \alpha_{y x}\right), \\
& a_{1}=\alpha_{x x} \phi_{\text {relative }}\left(i \omega_{c}\right)+\alpha_{y y} \phi_{\text {relative }}\left(i \omega_{c}\right) .
\end{aligned}
$$

The ratio of imaginary and real parts of eigenvalues can be expressed as follows:

$$
\kappa=\frac{\Lambda_{I}}{\Lambda_{R}}=\tan \left(\frac{\pi}{2}-\frac{\omega_{c} T}{2}\right) .
$$

By solving the above equation, the relationship between spindle speed and frequency of chatter, $\omega_{c}$, can be calculated as follows:

$$
\begin{aligned}
& \omega_{c} T=\pi-2 \psi+2 k \pi, \\
& n=\frac{60}{N T},
\end{aligned}
$$

where $k$ is an integer number of vibration waves within a tooth period.

As can be seen from Eq. (12), the coefficients of cutting force are one of the parameters affecting the chatter stability region of the system. Therefore, in the next section, the cutting force coefficients have been determined by performing the experimental test.

\subsection{Identification of cutting force coefficients}

The general form of force relations for the tangential $\left(F_{t}\right)$ and radial $\left(F_{r}\right)$ components of cutting force for the milling process are as follows [42]:

$$
\begin{aligned}
& F_{t}=K_{t c} b h+K_{t e} b, \\
& F_{r}=K_{r c} b h+K_{r e} b,
\end{aligned}
$$

where $K_{t c}$ and $K_{r c}$ are the cutting coefficients of force in tangential and radial directions, respectively; $K_{t e}$ and $K_{r e}$ are edge coefficients of force in tangential and radial directions, respectively; and $b$ is the DOC and $h$ is the thickness of the chip and can be expressed as:

$$
h=c \sin \phi
$$

where $c$ is the feed rate per tooth and $\phi$ is the immersion angle. As shown in Figure 9 the components of the milling forces in $x$ and $y$ directions can be formulated as follows: 


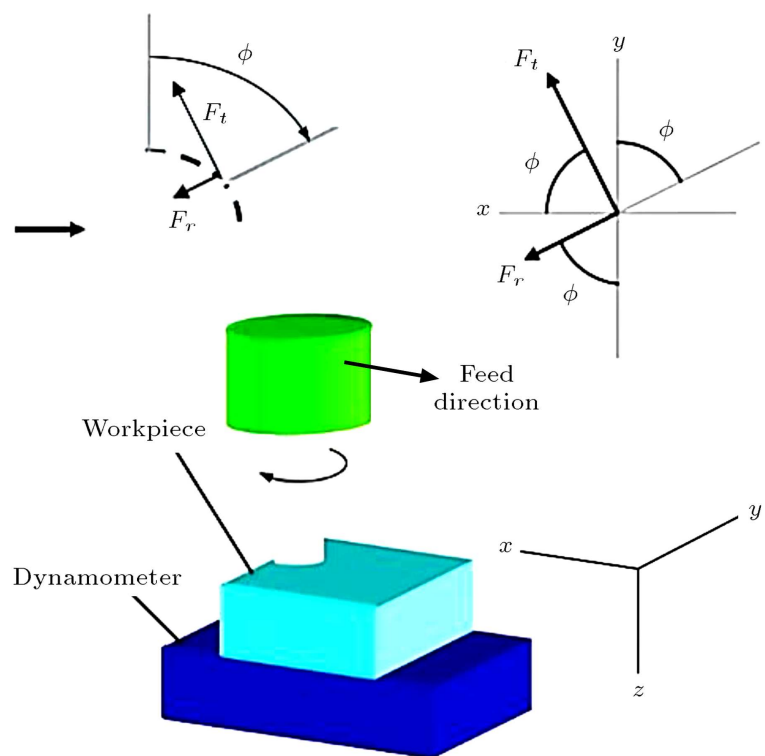

Figure 9. Components of cutting forces in $x$ and $y$ directions [43].

$$
\begin{aligned}
& F_{x}=F_{t} \cos \phi+F_{r} \sin \phi, \\
& F_{y}=F_{t} \sin \phi-F_{r} \cos \phi .
\end{aligned}
$$

By substituting Eqs. (19) to (21) in Eqs. (22) and (23), the total milling force for end-mill with $N$ number of teeth is obtained as follows:

$$
\begin{aligned}
F_{x}= & \sum_{j=1}^{N}\left(K_{t c} a c \frac{\sin 2 \phi_{j}}{2}+K_{t e} a \cos \phi_{j}\right. \\
& \left.+K_{r c} a c \frac{1-\cos 2 \phi_{j}}{2}+K_{r e} a \sin \phi_{j}\right) g\left(\phi_{j}\right), \\
F_{y}= & \sum_{j=1}^{N}\left(K_{t c} a c \frac{1-\cos 2 \phi_{j}}{2}+K_{t e} a \sin \phi_{j}\right. \\
& \left.-K_{r c} a c \frac{\sin 2 \phi_{j}}{2}-K_{r e} a \cos \phi_{j}\right) g\left(\phi_{j}\right),
\end{aligned}
$$

where $g\left(\phi_{j}\right)$ is the unit step function, which shows the state of the cutting edge engagement and is expressed as:

$$
g\left(\phi_{j}\right)=\left\{\begin{array}{ll}
1 & \text { if } \phi_{s t}<\phi_{j}<\phi_{e x} \\
0 & \text { if } \phi_{j}<\phi_{s t} \text { or } \phi_{j}>\phi_{e x}
\end{array}\right\}
$$

where, $\phi_{s t}$ and $\phi_{e x}$ are entry and exit angles of the tool, respectively. By integrating Eqs. (24) and (25) in the $\left[\begin{array}{ll}\phi_{s t} & \phi_{e x}\end{array}\right]$ interval and taking into account the groove machining conditions $\left(\phi_{s t}=0\right.$ and $\left.\phi_{e x}=\pi\right)$, the average force per tooth is calculated as below:
Table 5. Cutting parameters of groove-milling experiments.

\begin{tabular}{ccl}
$\begin{array}{c}\text { Experiment } \\
\text { no. }\end{array}$ & $\begin{array}{c}\text { Axial DOC } \\
(\mathbf{m m})\end{array}$ & $\begin{array}{c}\text { Spindle speed } \\
(\mathbf{R P M})\end{array}$ \\
\hline 1 & 3 & 700 \\
2 & 3 & 500 \\
3 & 2 & 700 \\
4 & 2 & 500 \\
5 & 1 & 1000 \\
6 & 1 & 700 \\
\hline
\end{tabular}

$$
\begin{aligned}
& \bar{F}_{x}=\frac{N a K_{r c}}{4} c+\frac{N a K_{r e}}{\pi}, \\
& \bar{F}_{y}=\frac{N a K_{t c}}{4} c+\frac{N a K_{t c}}{\pi} .
\end{aligned}
$$

According to Eqs. (27) and (28), the average force per tooth is a linear function of feed rates. Also one can obtain cutting coefficients of force by deriving the mentioned equations. For this purpose, six groups of groove-milling experiments, with the conditions shown in Table 5 were carried out. In each test, first, the average cutting force in the $x$ and $y$ directions was measured in 7 different values of feed rates i.e., $c=$ $[0.01,0.025,0.04,0.055,0.07,0.085,0.1] \mathrm{mm} / \mathrm{th}$, constant spindle speed and axial DOC. For this purpose, the dynamometer type KISTLER 9257B is placed on a three-axis CNC milling table and an aluminum block (AL7075) is mounted on it (Figure 10). Next, using a 4-edge end-mill, mentioned six groups of groove-milling experiments, were carried out.

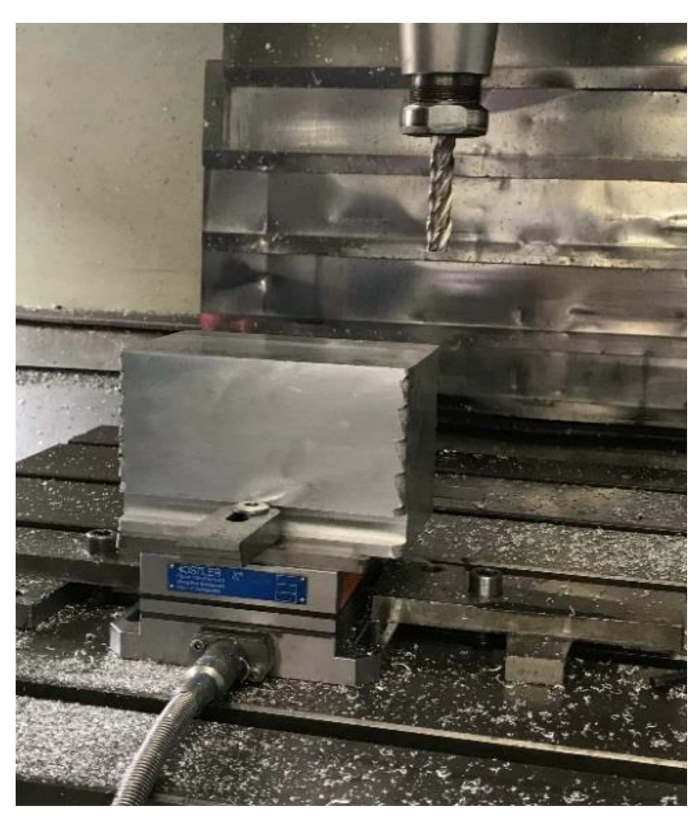

Figure 10. Measuring the cutting forces in groove milling. 


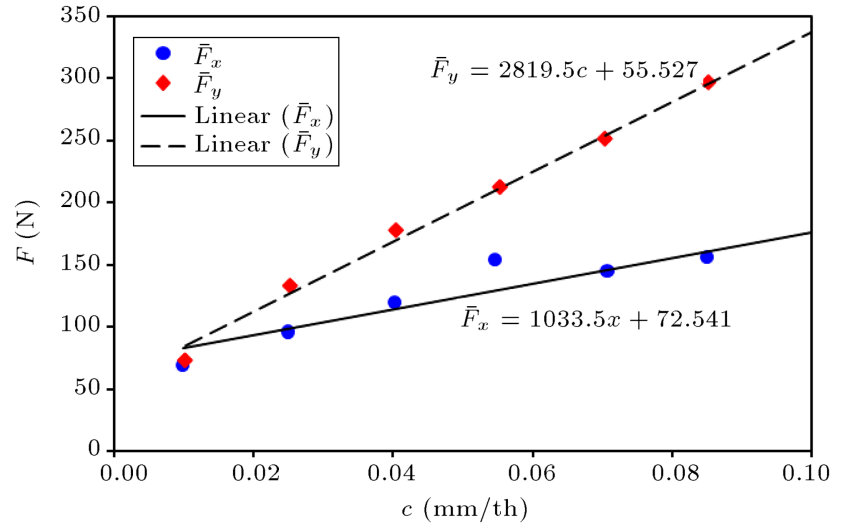

Figure 11. Average cutting force in $x$ and $y$ directions for different values of feed rate.

In each of these test sets, the average cutting force in the $x$ and $y$ directions was measured in the different values of feed rates. For example, the average cutting force versus feed rate in $x$ and $y$ directions for the first case of the experiment is illustrated in Figure 11. By fitting the curve on the data and using Eqs. (27) and (28), the cutting coefficients $K_{r c}=344.5 \mathrm{MPa}$ and $K_{t c}=939.83 \mathrm{MPa}$ are obtained for the first case test. Finally, the cutting coefficients are obtained as $K_{r c}=$ $309.94 \mathrm{MPa}$ and $K_{t c}=964.42 \mathrm{MPa}$ by averaging the results of all experiment cases.

\subsection{Effect of workpiece and tool dimensions on the chatter stability region}

Figure 12 shows the SLDs for three different workpiece heights, $L=60 \mathrm{~mm}, L=70 \mathrm{~mm}$, and $L=80 \mathrm{~mm}$, for a thin-walled 7075 aluminum workpiece with a width of $40 \mathrm{~mm}$ and a thickness of $6 \mathrm{~mm}$. Radial DOC was taken $4 \mathrm{~mm}$ and the values of other parameters are the same as Sections 2.1 and 2.2. As can be seen in Figure 12, with increasing the height of the workpiece, the stability lobes moved downward and the stability region of the system decreased. The reason for decreasing the stability region of the system

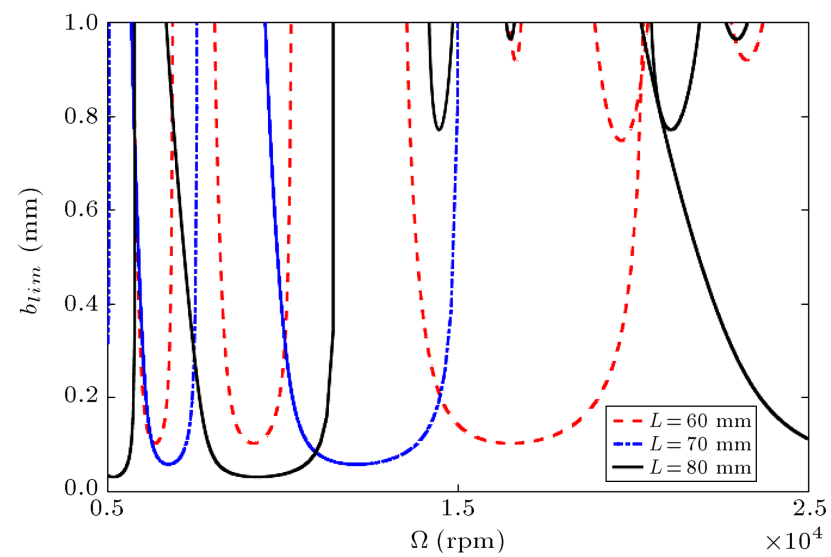

Figure 12. Stability lobe diagram for three different workpiece heights.

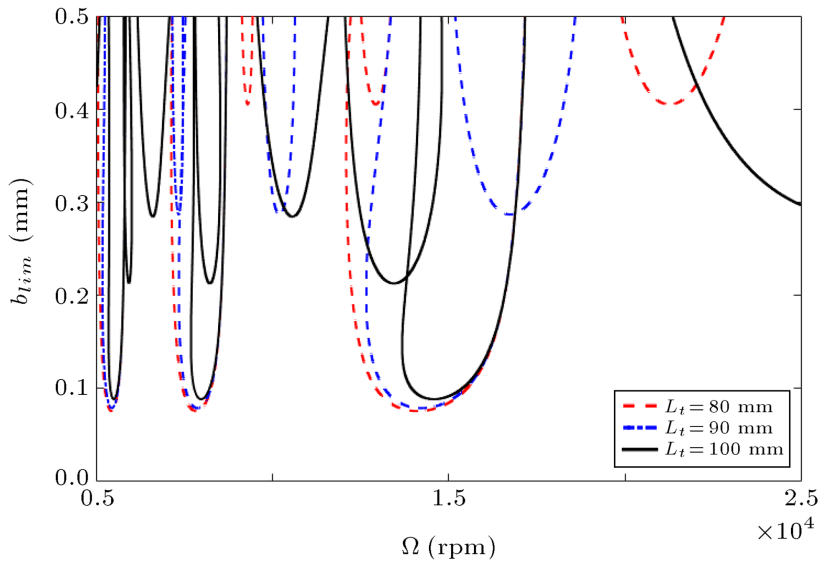

Figure 13. Stability lobe diagram for three different tool lengths.

is that as the height of the workpiece increases the stiffness of the system decreases. Also, as can be seen from the mentioned figure, the lobes move leftwards by increasing the height of the workpiece. The reason for this is that as the height of the workpiece rises, the natural frequencies of the workpiece fall, causing the lobes to shift to the left.

Moreover the SLDs for three different tool lengths, $L_{t}=80 \mathrm{~mm}, L_{t}=90 \mathrm{~mm}$, and $L_{t}=100 \mathrm{~mm}$ are presented in Figure 13. As seen in this figure, the stability region decreases as the length of the tool increases.

\subsection{Three dimensional SLD based on the geometrical parameter of the system}

As shown earlier, to define the stability region of the machining process the vibrational tests are necessary. In practice, however, no vibration equipment or specialists are available in all workshops to predict the stability boundaries. Therefore three-dimensional stability diagrams based on the geometrical parameters of the machining system are presented.

In Figure 14, three-dimensional SLD is illustrated for different values of workpiece thickness/workpiece

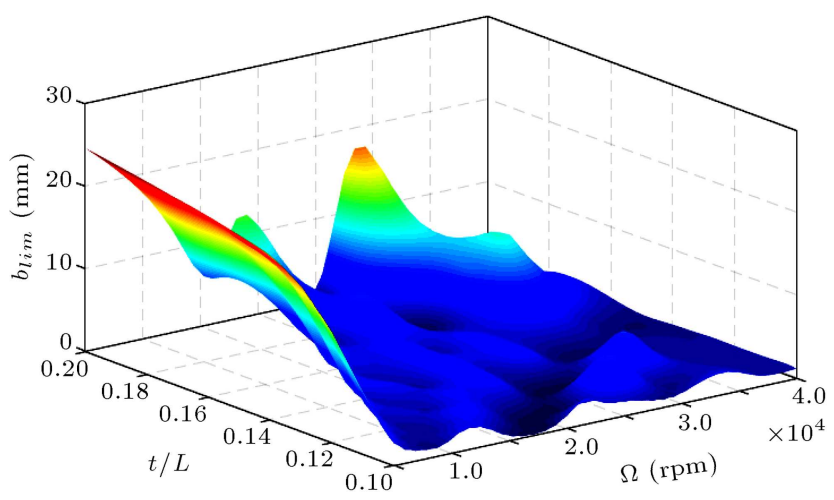

Figure 14. Three dimensional stability lobe diagram in terms of the workpiece thickness/height ratio. 
height ratio. As can be seen from this figure, increasing the value of thickness/height ratio causes the stable cutting depth to increase. The reason for this is that, with increasing the mentioned ratio, the stiffness of the workpiece increases and as a result, the probability of chatter occurrence decreases. In Figure 15, we plotted the three-dimensional SLD based on the geometrical parameters of the tool. In this diagram $y$-axis is the ratio of tool diameter to its overhang length. Two sets of machining experiments were conducted and the machining force was measured by the dynamometer to demonstrate the application of the 3D SLDs. For the first case, the spindle speed was $11000 \mathrm{rpm}$, axial DOC was $1 \mathrm{~mm}$ and radial DOC was $4 \mathrm{~mm}$, the tool overhang length was $90 \mathrm{~mm}$, tool diameter was $20 \mathrm{~mm}$ and the number of tool teeth was chosen 4 . The FFT of force signal related to the first set of experiments is shown in Figure 16. As can be seen, a peak with a large amplitude is observed near the first natural frequency of the workpiece $(1171.4 \mathrm{~Hz})$, which indicates the occurrence of chatter.

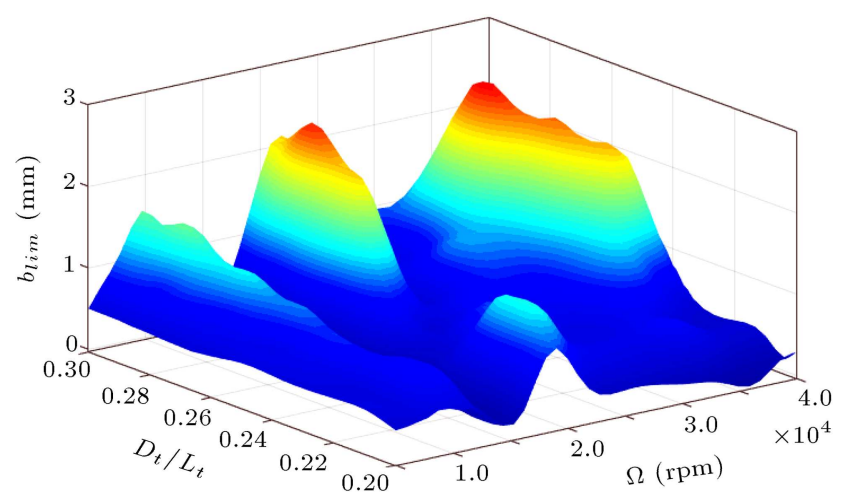

Figure 15. Three dimensional stability lobe diagram in terms of the tool diameter/overhang length ratio.

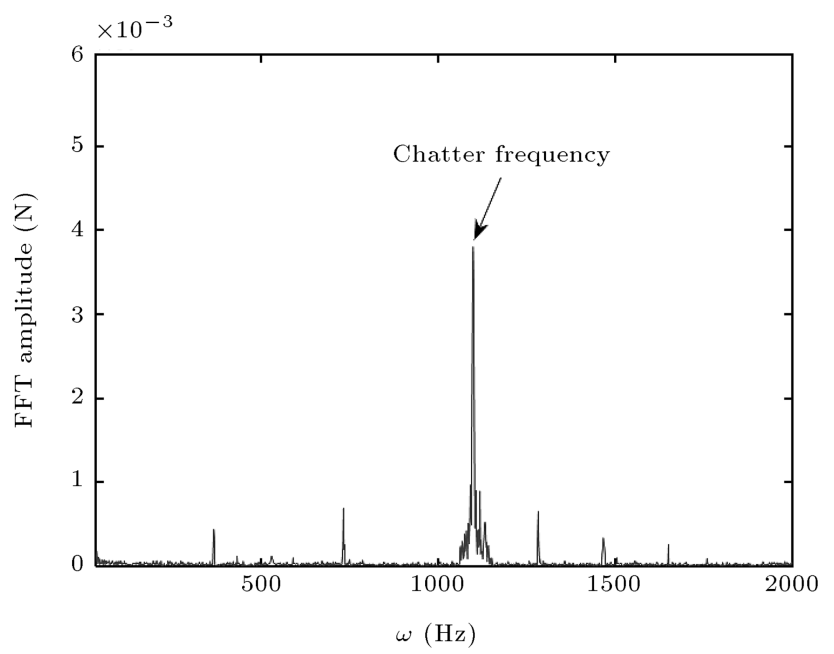

Figure 16. The machining force in the milling process of thin-walled part in the frequency domain for a tool with a length of $90 \mathrm{~mm}$.

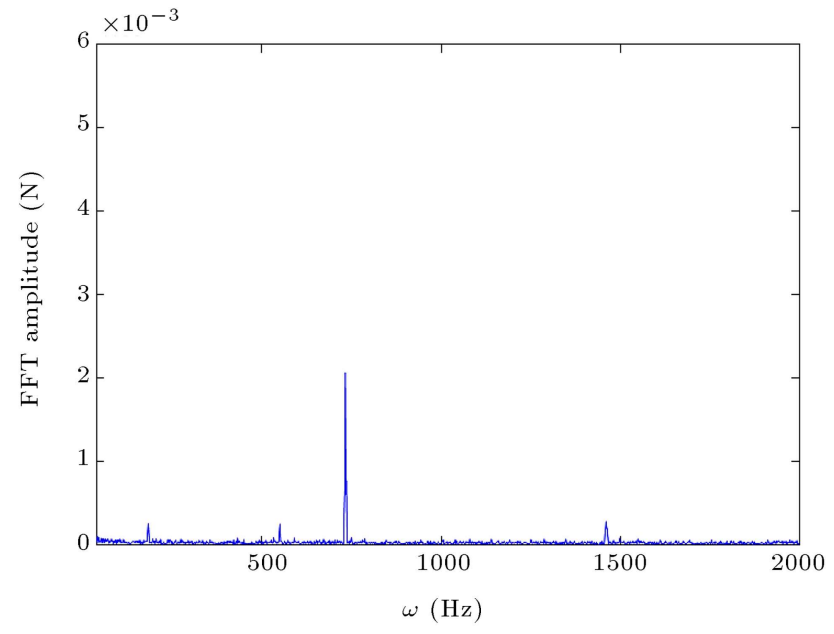

Figure 17. The machining force in the frequency domain for a tool length of $70 \mathrm{~mm}$.

Changing the tool overhang value to $70 \mathrm{~mm}$ $\left(D_{t} / L_{t}=0.28\right)$ prevented the chatter instability. In Figure 17, the FFT of the force signal of the second set of experiments is plotted. It can be seen that by reducing the overhang from 90 to 70 , no sign of chatter is observed.

\section{Conclusion}

In this paper, the stability of the milling process of thinwalled parts is investigated. For this purpose, first, the relative Transfer Function (TF) of the tool-workpiece has been acquired. Then the Stability Lobe Diagrams (SLDs) for the machining process are obtained and the effects of important parameters on the stability region are investigated. The results showed that by increasing the height of the workpiece, the probability of occurrence of chatter increased. Finally, threedimensional SLDs based on the geometrical parameters of the workpiece and tool are presented. As the findings show, one can avoid chatter instability by using threedimensional SLDs and simple dimensional measuring tools.

\section{Acknowledgment}

The authors hereby express their gratitude to the vibration laboratory of the University of Tabriz and the machining research laboratory of Sharif University of technology for letting us use the equipment of the laboratory and their assistance with the needed experiments.

\section{Nomenclature}

$\begin{array}{ll}\omega_{r} & \text { Natural frequency of } r \text { th mode } \\ \left\{\varphi_{r}\right\} & \text { Mass normalized mode shapes }\end{array}$


$\eta_{r} \quad$ Structural damping ratio of $r$ th mode

$w(x, t) \quad$ Displacement of the beam at point $x$

$c \quad$ Rayleigh damping coefficient

EI Bending stiffness

$m \quad$ Mass per unit length of the beam

$\chi_{r}(t) \quad$ Modal coordinate

$\psi_{r}(x) \quad$ Mass normalized eigenfunction

$\kappa_{r} \quad$ Dimensionless frequency parameter

$K_{t} \quad$ Coefficient of tangential cutting force

$\Lambda_{R} \quad$ Real part of system's eigenvalues

$\omega_{c} \quad$ Frequency of chatter

$K_{t c} \quad$ Cutting coefficient of force in tangential direction

$K_{r c} \quad$ Cutting coefficient of force in radial direction

$K_{t e} \quad$ Edge coefficient of force in tangential direction

$K_{r e} \quad$ Edge coefficient of force in radial direction

$\phi \quad$ Immersion angle

$g\left(\phi_{j}\right) \quad$ Unit step function

$\phi_{s t} \quad$ Entry angle of the tool

$\phi_{e x} \quad$ Exit angle of the tool

\section{References}

1. Herranz, S., Campa, F., Lacalle, L.L., et al. "The milling of airframe components with low rigidity: a general approach to avoid static and dynamic problems", Proceedings of the Institution of Mechanical Engineers, Part B: Journal of Engineering Manufacture, 219, pp. 789-801 (2005).

2. Ding, Y. and Zhu, L. "Investigation on chatter stability of thin-walled parts considering its flexibility based on finite element analysis", The International Journal of Advanced Manufacturing Technology, 94, pp. 31733187 (2018).

3. Sunilsing, R. and Deshmukh, D. "Experimental analysis of regenerative chatter in BFW vertical milling machine", International Journal of Innovative Research in Science, Engineering and Technology, 3, pp. 1373113739 (2014).

4. Insperger, T., Mann, B.P., Stépán, G., and Bayly, P.V. "Stability of up-milling and down-milling, part 1: alternative analytical methods", International Journal of Machine Tools and Manufacture, 43, pp. 25-34 (2003).

5. Otto, A., Rauh, S., Kolouch, M., and Radons, G. "Extension of Tlusty's law for the identification of chatter stability lobes in multi-dimensional cutting processes", International Journal of Machine Tools and Manufacture, 82, pp. 50-58 (2014).

6. Tobias, S.A. and Fishwick, W., A Theory of Regenerative Chatter, The Engineer London (1958).
7. Tlusty, J. and Polacek, M. "The Stability of the machine tool against self-excited vibration in machining", ASME Int. Res. in Production, 1, pp. 465-474 (1963).

8. Tang, A.J. and Liu, Z.Q. "Effect of helix angle and normal rake angle on stability in end milling", Advanced Materials Research, 69, pp. 394-398 (2009).

9. Seguy, S., Campa, F.J., Lacalle, L.L., Arnaud, L., Dessein, G., and Aramendi, G., "Toolpath dependent stability lobes for the milling of thin-walled parts", International Journal of Machining and Machinability of Materials, 4, pp. 377-392 (2008).

10. Gonzalo, O., Peigneé, G., and Gonzaález, D. "High speed machining simulation of thin-walled components", In Proceedings of 5th International Conference on High Speed Machining, University of Metz, Metz, France (2006).

11. Campa, F.J., Seguy, S., Lacalle, L.L., Arnaud, L., Dessein, G., and Aramendi, G. "Stable milling of thin-walled parts with variable dynamics", Tekniker, Ed., In 6th International Conference on High Speed Machining, San Sebastiaán, Spain (2007).

12. Campa, F.J., Lacalle, L.L., Urbikain, G., and Ruiz, D. "Definition of cutting conditions for thin-to-thin milling of aerospace low rigidity parts", In International Manufacturing Science and Engineering Conference, 48517, pp. 359-368 (2008).

13. Song, Q.H., Wan, Y., Yu, S.Q., Ai, X., and Pang, J.Y. "Stability prediction during thin-walled workpiece high-speed milling", Advanced Materials Research, 69-70, pp. 428-432 (2009).

14. Tang, A. and Liu, Z. "Three-dimensional stability lobe and maximum material removal rate in end milling of thin-walled plate", Int. J. Adv. Manuf. Technol., 43, pp. 33-39 (2009).

15. Ismail, F. and Ziaei, R. "Chatter suppression in fiveaxis machining of flexible parts", International Journal of Machine Tools and Manufacture, 42, pp. 115-122 (2002).

16. Bravo, U., Altuzarra, O., Lacalle, L.L., Sánchez, J.A., and Campa, F.J. "Stability limits of milling considering the flexibility of the workpiece and the machine", International Journal of Machine Tools and Manufacture, 45, pp. 1669-1680 (2005).

17. Mañé, I., Gagnol, V., Bouzgarrou, B.C., and Ray, P. "Stability-based spindle speed control during flexible workpiece high-speed milling", International Journal of Machine Tools and Manufacture, 48, pp. 184-194 (2008).

18. Seguy, S., Dessein, G., and Arnaud, L. "Surface roughness variation of thin wall milling, related to modal interactions", International Journal of Machine Tools and Manufacture, 48, pp. 261-274 (2008).

19. Atlar, S., Budak, E., and Özgüven, H.N. "Modeling part dynamics and chatter stability in machining considering material removal", In 1st International Conference on Process Machine Interactions, Hannover, pp. 61-72 (2008). 
20. Zhang, X., Xiong, C., and Ding, Y. "A new solution for stability prediction in flexible part milling", In International Conference on Intelligent Robotics and Applications, Berlin, Heidelberg, pp. 452-464 (2011).

21. Budak, E., Tunç, L.T., Alan S., and Özgüven, H.N. "Prediction of workpiece dynamics and its effects on chatter stability in milling", CIRP Annals - Manufacturing Technology, 61, pp. 339-342 (2012).

22. Powałka, B. and Jemielniak, K. "Stability analysis in milling of flexible parts based on operational modal analysis", CIRP Journal of Manufacturing Science and Technology, 9, pp. 125-135 (2015).

23. Wan, M., Dang, X.B., Zhang, W.H., and Yang, Y. "Optimization and improvement of stable processing condition by attaching additional masses for milling of thin-walled workpiece", Mechanical Systems and Signal Processing, 103, pp. 196-215 (2018).

24. Wan, M., Gao, T.Q., Feng, J., and Zhang, W.H. "On improving chatter stability of thin-wall milling by prestressing", Journal of Materials Processing Technology, 264, pp. 32-44 (2019).

25. Yan, B. and Zhu, L. "Research on milling stability of thin-walled parts based on improved multifrequency solution", The International Journal of Advanced Manufacturing Technology, 102(1-4), pp. 431441 (2019).

26. Zhu, L., Liu, B., and Chen, H. "Research on chatter stability in milling and parameter optimization based on process damping", Journal of Vibration and Control, 24(12), pp. 2642-2655 (2018).

27. Wan, S., Jin, X., Maroju, N.K., and Hong, J. "Effect of vibration assistance on chatter stability in milling", International Journal of Machine Tools and Manufacture, 145, p. 103432 (2019).

28. Liu, B., Zhu, L., Dun, Y., and Liu, C. "Investigation on chatter stability of thin-walled parts in milling based on process damping with relative transfer functions", The International Journal of Advanced Manufacturing Technology, 89(9-12), pp. 2701-2711 (2017).

29. Liu, C., Zhu, L., and Ni, C. "Chatter detection in milling process based on VMD and energy entropy", Mechanical Systems and Signal Processing, 105, pp. 169-182 (2018).

30. Wan, S., Li, X., Su, W., Yuan, J., and Hong, J. "Active chatter suppression for milling process with sliding mode control and electromagnetic actuator", Mechanical Systems and Signal Processing, 136, p. 106528 (2020).

31. Wu, G., Li, G., Pan, W., Wang, X., and Ding, S. "A prediction model for the milling of thin-wall parts considering thermal-mechanical coupling and tool wear", International Journal of Advanced Manufacturing Technology, 107(11-12), pp. 4645-4659 (2020).

32. Xia, Y., Wan, Y., Luo, X., et al. "Development of a toolholder with high dynamic stiffness for mitigating chatter and improving machining efficiency in face milling", Mechanical Systems and Signal Processing, 145, p. 106928 (2020).

33. Altintas, Y., Stepan, G., Budak, E., Schmitz, T., and Kilic, Z.M. "Chatter stability of machining operations", Journal of Manufacturing Science and Engineering, 142, pp. 110801-110819 (2020).

34. Zhu, L. and Liu, C. "Recent progress of chatter prediction, detection and suppression in milling", Mechanical Systems and Signal Processing, 143, p. 106840 (2020).

35. Dun, Y., Zhu, L., and Wang, S. "Multi-modal method for chatter stability prediction and control in milling of thin-walled workpiece", Applied Mathematical Modelling, 80, pp. 602-624 (2020).

36. Dang, X.B., Wan, M., Zhang, W.H., and Yang, Y. "Chatter analysis and mitigation of milling of the pocket-shaped thin-walled workpieces with viscous fluid", International Journal of Mechanical Sciences, 194, p. 106214 (2021).

37. Zhu, L., Liu, C., Ju, C., and Guo, M. "Vibration recognition for peripheral milling thin-walled workpieces using sample entropy and energy entropy", The International Journal of Advanced Manufacturing Technology, 108(9), pp. 3251-3266 (2020).

38. Eksioglu, C., Kilic, Z.M., and Altintas, Y. "Discretetime prediction of chatter stability, cutting forces, and surface location errors in flexible milling systems", Journal of Manufacturing Science and Engineering, 134(6), p. 061006 (2012).

39. Leissa, A.W., Vibration of Plates, Ohio State Univ Columbus (1969).

40. Rezaee, M., Yam, G.F., and Fathi, R. "Development of modal analysis free vibration response only method for randomly excited systems", Acta Mechanica, 226(12), pp. 4031-4042 (2015).

41. Budak, E. and Altintas, Y. "Analytical prediction of chatter stability in milling-part I: general formulation", Journal of Dynamic Systems, Measurement, and Control, 120, pp. 22-30 (1998).

42. Altintas, Y., Manufacturing Automation: Metal Cutting Mechanics, Machine Tool Vibrations, and CNC Design, Cambridge University Press (2000).

43. Schmitz, T.L. and Smith, K.S., Machining Dynamics : Frequency Response to Improved Productivity, Springer (2009).

\section{Biographies}

Mehran Mahboubkhah was born in 1975. He is Associate Professor in the Department of Mechanical Engineering at University of Tabriz, Iran. He obtained his BSc degree from Amirkabir University of Technology, Iran in 1998, his MSc degree from Sharif University of Technology (SUT), Iran in 2000, and his $\mathrm{PhD}$ degree from the University of Tarbiat Modares, Iran in 2007, all in Mechanical Engineering, Manufacturing branch. His research interests include machining 
and machine tool dynamics, design of machine tool structure, Parallel Kinematic Machine tools (PKMs), and metrology.

Mohamad Reza Movahhedy received his BSc degree from the University of Tehran, Iran in 1988, his MSc degree from University of Waterloo, Canada in 1994, and his $\mathrm{PhD}$ degree from University of British Colombia, Canada in 2000, all in Mechanical Engineering. He is currently a Professor in the Department of Mechanical Engineering at Sharif University of Technology (SUT), Iran. His research interests are FEM simulation of metal cutting/forming processes, machining and machine tool dynamics, mechanics of machining process, experimental modal analysis, and computer-aided tolerancing.
Amir Jodeiri Feizi received his BSc degree from the University of Tabriz, Iran in 2000, his MSc degree from Sharif University of Technology (SUT), Iran in 2003, all in the Mechanical Engineering, Manufacturing branch. He started his work as a precision measurement expert in the Metrology Laboratory of Iran Tractor Manufacturing Company (ITMCO), Iran. He continued his profession as a machining process designer in Saipa Engineering and Manufacturing of Equipment and Tools company (SEMETCO), Iran. Since then he is a PhD student of Mechanical Engineering, Manufacturing branch, at Mechanical Engineering Department of the University of Tabriz, Iran. Working on his PhD thesis made him experienced in the Modal Test of machine tools and machining process. His research interests are in machining and metrology. 